\title{
Failure to Thrive: Bad Nutrition as a Double-Edged Sword - A Case Report
}

Carla Veiga Rodrigues*, Sara Rocha, Ana Lima, Ana Marques Pinho, Marisa Santos, Teresa Botelho Patrício and Gabriela Pereira

USCP S Neutel, Portugal

*Corresponding author: Carla Veiga R, USCP S Neutel, Portugal, Tel: 00351911979387; E-mail: carla.veiga.rodrigues@gmail.com

Received date: November 01, 2017; Accepted date: December 22, 2017; Published date: December 29, 2017

Copyright: (C) 2017 Veiga RC, et al. This is an open-access article distributed under the terms of the Creative Commons Attribution License, which permits unrestricted use, distribution, and reproduction in any medium, provided the original author and source are credited.

\begin{abstract}
Introduction: Failure to thrive (FT) is a condition often seen by General Practitioners, characterized by a weight below the 5th percentile repeatedly or a weight deceleration crossing 2 major percentile lines. The majority of FT is due to inadequate caloric intake, mostly caused by behavioural/social issues.

The diagnosis is clinical and demands thorough investigation of feeding habits and exclusion of other organic causes. Differential diagnosis includes prenatal or chronic illness, infections or digestive disorders, which should be investigated and sought on physical examination and additional testing.

Case description: 3 year old girl with FT and microcephaly. History of social problems that caused visits from Social Services. Support from Nutrition Department was provided. The physical examination was consistently normal and other symptoms were denied, without improvement on the weight.

The initial investigation was normal, but, on a secondary level, sweat testing showed high Chloride (66 mEq/L) levels.

Discussion: The prognosis of FT depends on its severity, duration and subjacent cause. In this case, the biggest suspicion is malnourishment due to social problems. The positive chloride value often diagnoses Cystic Fibrosis, but it can also be a false positive caused by anorexia/bad nutrition. Malnourishment is a double-edged sword because of its ability to mask chronic illness, meaning either a cause or a result of it.

Conclusion: Identifying the problem underneath remains challenging due to our lack of control or knowledge of the real eating habits of our patients. A multidisciplinary approach is mandatory, as the effects of FT on cognitive development are unclear.
\end{abstract}

Keywords: Failure to thrive (FT); Sweat test; Cystic fibrosis (CF)

\section{Introduction}

Failure to thrive (FT) is a condition often seen by General Practitioners and Paediatricians, being one of the reasons for paediatric referral. The term is often used for infants and children with weight below the 5th percentile for sex and corrected age and supporting definitions include weight for length below the 5th percentile; body mass index for age below the 5th percentile; or a sustained decrease in growth velocity, in which weight for age or weight for length/height falls by two major percentiles over time [1]. The estimated prevalence is $5-10 \%$ in developed countries [2]. Etiology of FT can be divided into non-organic or functional cause, organic cause or combination of mechanisms [3] (Table 1).
The most frequent causes of FT are due to inadequate caloric intake, which includes gastroesophageal reflux, inadequate breast milk supply, incorrect formula preparation, mechanical feeding difficulties, neglect or abuse, poor feeding habits or poor oral neuromotor coordination [1]. Other situations that cause inadequate nutrient absorption (anaemia, iron deficiency, celiac disease, infections, cystic fibrosis, milk protein allergy) or increased energy requirements (chronic infection, chronic lung disease of prematurity, congenital heart disease, hyperthyroidism, inflammatory conditions, malignancy) should also be taken into account as possible etiologies [1].

The diagnosis is clinical and demands thorough history, physical examination and growth parameters documented over time [1].

\section{Non-Organic Causes}

Psychosocial Causes

- Lack of affection

- Cultural/Religious beliefs

- Family psychiatric diseases (depression and anxiety) 
Citation: Veiga CR, Sara R, Ana L, Ana Marques P, Marisa S, et al. (2017) Failure to Thrive: Bad Nutrition as a Double-Edged Sword - A Case Report. Primary Health Care 7: 287. doi:10.4172/2167-1079.1000287

Page 2 of 6

\begin{tabular}{|c|c|}
\hline & - Family dysfunction \\
\hline & - Neglect and abuse \\
\hline & - Poverty \\
\hline & - Munchausen syndrome by proxy \\
\hline \multirow{8}{*}{ Dietary errors } & - Anorexia \\
\hline & - Lack of knowledge of the child's nutritional needs \\
\hline & - Difficulties in breastfeeding \\
\hline & - Iron and zinc deficiency \\
\hline & - Avoidance of hyper caloric food \\
\hline & - Incorrect formula preparation \\
\hline & - Poor transition to solid food \\
\hline & - Poor feeding habits \\
\hline \multicolumn{2}{|r|}{ Organic Causes } \\
\hline \multirow{5}{*}{ Cardiovascular disease } & - Severe asthma \\
\hline & - Chronic lung disease of prematurity \\
\hline & - Congenital heart disease \\
\hline & - Bronchopulmonary dysplasia \\
\hline & - Cystic Fibrosis \\
\hline \multirow{9}{*}{ Gastrointestinal disease } & - Food allergy \\
\hline & - Gastroesophageal reflux \\
\hline & - Celiac disease \\
\hline & - Hirschsprung disease \\
\hline & - Chronic gastrointestinal conditions (e.g. irritable bowel syndrome) \\
\hline & - Gastrointestinal infections \\
\hline & - Biliary atresia \\
\hline & - Milk protein allergy \\
\hline & - Pancreatic cholestatic conditions \\
\hline \multirow{2}{*}{ Renal disease } & - Renal failure \\
\hline & - Recurrent urinary infection \\
\hline \multirow{2}{*}{ Central nervous system disease } & - Cerebral paralysis \\
\hline & - Neuromuscular disease \\
\hline \multirow{3}{*}{ Endocrine disease } & - Hyperthyroidism \\
\hline & - Diabetes Mellitus \\
\hline & - Primary hyperaldosteronism \\
\hline \multirow{2}{*}{ Hematologic disease } & - Anaemia \\
\hline & - Iron deficiency \\
\hline
\end{tabular}


Citation: Veiga CR, Sara R, Ana L, Ana Marques P, Marisa S, et al. (2017) Failure to Thrive: Bad Nutrition as a Double-Edged Sword - A Case Report. Primary Health Care 7: 287. doi:10.4172/2167-1079.1000287

Page 3 of 6

\begin{tabular}{|l|l|}
\hline \multirow{4}{*}{ Infectious disease } & - Major thalassemia \\
\hline & - Human Immunodeficiency virus (HIV) \\
\cline { 2 - 2 } & - Recurrent infections \\
\cline { 2 - 2 } & - Pulmonary tuberculosis \\
\hline \multirow{2}{*}{ Others diseases } & - Obstructive sleep apnea \\
\cline { 2 - 3 } & - - Congenital immunodeficiency \\
\hline
\end{tabular}

Table 1: Etiology of failure to thrive.

Regarding medical history, it is vital to observe child-parent's interaction, investigate the obstetric history and parent's height and weight, as well as daily routine in what comes to feeding habits [2]. Concerning physical examination, it must be complete and detailed, looking for possible changes that may indicate any chronic or acute illness, recognition of dysmorphology suggesting a genetic condition, assessment for normal development and quantification of the degree of under nutrition [2].

Laboratory tests and imaging can be useful but should always be solicited considering clinical suspicion provided by history and physical examination [2] (Table 2).

\begin{tabular}{|c|c|}
\hline \multirow{15}{*}{ First Level } & - Hemogram with platelets \\
\hline & - Glycemia \\
\hline & - Sodium, potassium, chloride, calcium and phosphorus \\
\hline & - Urea and creatinine \\
\hline & - Ast, alt, ggt, alkaline phosphatase \\
\hline & - Total protein and albumin \\
\hline & - Iron kinetics \\
\hline & - Sedimentation rate \\
\hline & - Gasometry \\
\hline & - Urine analysis and culture \\
\hline & - Coproculture \\
\hline & - Celiac disease serology \\
\hline & - Immunoglobulins dosing \\
\hline & - Sweat test \\
\hline & - Tuberculin test \\
\hline & - Faecal fat quantification \\
\hline & - Faecal occult blood test \\
\hline & - Thyroid function \\
\hline & - Total IgE, specific cow's milk proteins IgE, suspected-IgE mediated food \\
\hline Second Level & - Toxoplasma, rubella, cytomegalovirus, herpes, HIV and syphilis serologies \\
\hline & - Renal ultrasound \\
\hline & - Abdominal ultrasound \\
\hline & - Echocardiogram \\
\hline & - Lactose intolerance test \\
\hline
\end{tabular}




\begin{tabular}{|c|c|}
\hline & - Prealbumin e cystatin c (when indicated by first level exams) \\
\hline \multirow{4}{*}{ Third Level } & $\begin{array}{c}\text { - Metabolic study: ammonia, lactate, pyruvate, chromatography of serum and urinary amino acids, } \\
\text { chromatography of the urinary organic acids }\end{array}$ \\
\hline & - Sleep study \\
\hline & - Endoscopy and intestinal biopsy \\
\hline & - Subspecialties orientation depending on the pathology that was found \\
\hline
\end{tabular}

Table 2: Levels of complementary study of FT, AST: Aspartate Transaminase; ALT: Alanine Transaminase; GGT: Gamma Glutamyl Transferase; HIV: Human Immunodeficiency Virus.

\section{Case Description}

\section{Identification}

The present case concerns a 3 year old girl, healthy, whose weight was consistently below the 5 th percentile since birth, between the year 2013 and 2014. Cephalic perimeter followed the same percentile (3rd percentile) over consultations since birth. Both parameters are consistent with failure to thrive and microcephaly. For those reasons, the child was referred for Paediatric consultation on hospital setting.

The child is the first progeny of a Portuguese couple, residing in a small rural village in the northern interior area of the country. She's from a nuclear family with 3 elements and going through 3rd stage of Duvall's family life cycle. The family's income is low and uncertain as both parents are unemployed, with low Graffar score.

Pregnancy occurred without complications such as infections, placental insufficiency or uterine growth restrictions. Labour happened on 39th week of pregnancy without history of anoxia or trauma. Parents are reportedly healthy, deny current medications and fall within the 50th weight/height percentile, presenting no other significant family history. Regarding pathological history, the mother denies glucocorticoid intake for long periods or repetitive respiratory tract infections during the last year.

The child attends the local day-care and presents no evidence of psychomotor impairment, besides borderline normal cognitive and learning skills.

\section{Physical examination}

The child was hydrated, without jaundice, skin rashes, dysmorphic habitus or evident lesions. Otoscopic and oropharynx exams were normal and teeth had no cavities. Heart and lung auscultation was symmetric, without murmurs, sibilance or crepitation. Abdomen was soft, without abnormal tympanist and no organometal were palpated. Both limbs were symmetrical, with proper muscular tonus and without signs of acro-dimorphism. No edema, queilitis, fragile nails or alopecia were verified when searching for signs of malnourishment. Craniostenostosis was early excluded and the head was symmetrical. The neurological examination was normal, without signs of cerebral palsy, ataxic gait or other anomalies related to oral-motor dysfunctions.

No signs pointing towards child abuse or repetitive trauma were found. Nutritional status was evaluated and the mother reported adequate diversification during the neonatal period and proper feeding habits. Sleeping patterns were inquired and reportedly within 9 to $10 \mathrm{~h}$ of sleep each night, without noticeable snoring or apneas. No other symptoms or complaints were reported and the child presented herself in consultation with adequate social skills.

To ensure adequate feeding routine, the child was referred to a Nutrition consultation.

As predicted by the first level of investigations, exams were ordered. The results showed blood tests without anaemia and normal electrolytic, renal, thyroid and liver function. Blood gasometric study was normal and no anti-transglutaminase antibodies were found. Urine culture, RAST for cow's milk proteins, IgE testing and parasite faecal testing were all negative. Mantoux testing came out negative [3].

On a secondary level, abdominal ultrasound, brain CT and brain MRI were taken and presented no significant alterations. Genetic studies were performed and the karyotype was 46,XX. Finally, a sweat test was requested and results showed $66 \mathrm{mEq} / \mathrm{L}$ chloride, which classifies as positive sweat test (normal range: below $40 \mathrm{mEq} / \mathrm{L}$ ) [4].

For a year period, the child missed the follow-up appointments. Social Services initiated programmed visits to the family, suspecting neglect from the caregiver (mother) [3].

They returned to the appointments in January 2015, with 3 years and 10 months age, $13 \mathrm{~kg}$ of weight (P5-10) and $95 \mathrm{~cm}$ of height (P10-25), with slight weight recovery. There were no respiratory or gastrointestinal complaints. The sweat test was repeated, this time with a value of $43 \mathrm{mEq} / \mathrm{L}$, qualifying as a doubtful result (dubious test range: $40-60 \mathrm{mEq} / \mathrm{L})[4]$.

Three months later, the patient returned to the appointments. Concerning height and weight percentiles, the patient maintained the $5^{\text {th }}$ and $10-25^{\text {th }}$ percentiles, respectively. The sweat test was repeated, showing $56 \mathrm{mEq} / \mathrm{L}$ of chloride and genetic mutations for cystic fibrosis (CFTR) were tested and negative.

\section{Discussion}

The prognosis of FT depends on its severity, duration and subjacent cause.

The strongest initial suspicion was malnourishment due to social problems, but parental negligence was excluded by Social Services. Additionally, Cystic Fibrosis (CF) is a differential diagnosis to consider when evaluating FT and sweat test results can be misleading.

$\mathrm{CF}$ is an autosomal recessive disease involving mucus and sweat producing cells, affecting multiple organs, with lungs most severely affected. It comprises multiple respiratory and gastrointestinal complications like bronchiectasis and chronic infections that eventually lead to respiratory failure [5]. Concerning respiratory tract 
Page 5 of 6

infections and respiratory symptoms, these were all denied by the mother and there are no records of Emergency Room (ER) visits that could confirm this fact.

Growth failure in CF children is often due to deficient calorie intake, frequently related to elevated requirements of energy to meet the immune response to infection [6]. Other complications like hepatic dysfunction, gallstones and intestinal obstruction may also develop in CF patients [5].

The diagnosis of CF is based on clinical history and to improve the diagnostic process, in 1998, the Cystic Fibrosis Foundation developed two tables for the required criteria. The identification should be based on the presence of 1 or more items from the Initial criteria and another item from the laboratory criteria $[4,7]$ (Table 3 ). Only $2 \%$ of infants are expected to remain undiagnosed or difficult to classify (limited clinical features, negative or inconclusive diagnostic tests) [4,8]. The initial criteria requires at least one phenotypic feature associated with $\mathrm{CF}$. These features are listed on Table 4. Taking this information into practice, this child appeared to have malnourishment, even though edema was not present and a positive sweat test, merging the needed criteria for the CF diagnosis.

\begin{tabular}{|c|c|}
\hline Initial criteria & Laboratory evidence of CFTR dysfunction \\
\hline At least one characteristic phenotypic feature & Two abnormal quantitative pilocarpine iontophoresis sweat chloride concentrations \\
\hline Sibling with diagnosed CF & Presence of 2 disease-causing mutations in the CFTR \\
\hline Positive NBS result & Demonstration of abnormal NPD \\
\hline
\end{tabular}

Table 3: Diagnostic criteria for CF. CF: Cystic Fibrosis; CFTR: Cystic Fibrosis Gene; NBS: New-Born Screening Test; NPD: Nasal Potential Difference.

\begin{tabular}{|c|c|}
\hline Chronic sinopulmonary disease & $\begin{array}{c}\text { Persistent colonisation/infection with typical CF pathogens including Staphylococcus aureus, non-typeable } \\
\text { Haemophilus influenza, mucoid and non-mucoid Pseudomonas aeruginosa and Burkholderia cepacia; } \\
\text { Chronic cough and sputum production; Persistent chest radiographic abnormalities; Airway obstruction } \\
\text { manifested by wheezing and air trapping; Nasal polyps; Imagiological abnormalities of the paranasal } \\
\text { sinuses; Digital clubbing }\end{array}$ \\
\hline Gastrointestinal and nutritional abnormalities & $\begin{array}{l}\text { Intestinal: meconium ileus, distal intestinal obstruction syndrome, rectal prolapse; Pancreatic: pancreatic } \\
\text { insufficiency, recurrent pancreatitis; Hepatic: chronic hepatic disease (evidence of focal biliary or multilobular } \\
\text { cirrhosis); Nutritional: failure to thrive (protein-calorie malnutrition), hypoproteinemia and edema, } \\
\text { complications secondary to fat-soluble vitamin deficiency }\end{array}$ \\
\hline Salt loss syndromes & Acute salt depletion; Chronic metabolic alkalosis \\
\hline Male urogenital abnormalities & Obstructive azoospermia (CBAVD) \\
\hline
\end{tabular}

Table 4: Characteristic phenotypic features. CBAVD: Congenital Bilateral Absence of the Vas Deferens.

The sweat test refers to the quantitative or qualitative analysis of sweat to measure electrolyte concentration, conductivity or osmolality for diagnosing CF [9]. It determines the amount of chloride excreted in sweat and it signals a positive test if chloride $>60 \mathrm{mEq} / \mathrm{L}$, uncertain if between 40 and $59 \mathrm{mEq} / \mathrm{L}$ and negative if $<40 \mathrm{mEq} / \mathrm{L}$ [4].

Uncertain or borderline sweat chloride results may set us by a diagnostic dilemma; during infancy, a value of $40 \mathrm{mEq} / \mathrm{L}$ or higher has a low probability of being a true normal. Careful follow-up, observation, repetition of the sweat test and CFTR analysis should be tested on designated infants with borderline values [10].

However, sweat testing is a demanding procedure and has its own deceiving, as most errors relate to use on unreliable methodology, inadequate sweat collect and technical errors [11].
Intermediate values can also be thought-provoking and Lebecque et al. [12] presented a study including 10 children with intermediate sweat chloride levels and a diagnosis of CF. Nevertheless, only 2 infants fulfilled the clinical and diagnostic criteria for CF [2].

Positive values for chloride testing can be a confusing factor too. There is a huge number of conditions that can elevate sweat electrolytes, generally easy to differentiate from CF and should not be considered true false positives, as the chloride value is expected to normalize once the condition has been treated (Table 5).

\begin{tabular}{|l|l|}
\hline Primary (True false positives) & Secondary \\
\hline Autonomic dysfunction & Anorexia nervosa \\
\hline Ectodermal dysplasia & Atopic dermatitis \\
\hline Familial cholestasis (Byler's disease) & Environmental deprivation \\
\hline
\end{tabular}


Page 6 of 6

\begin{tabular}{|l|l|}
\hline Fucosidosis & Nephrogenic diabetes insipidus \\
\hline Glucose-6-phosphate dehydrogenase deficiency & Nephrosis \\
\hline Glycogen storage disease type 1 Hypogammaglobulinemia & Protein-calorie malnutrition \\
\hline Klinefelter's syndrome & Pseudohypoaldosteronism \\
\hline \multirow{2}{*}{$\begin{array}{l}\text { Long-term prostaglandin E1 infusion Mauriac's syndrome } \\
\text { (malnutrition of) Mucopolysaccharidosis Type I }\end{array}$} & Psychosocial failure to thrive \\
\cline { 2 - 2 } & Untreated adrenal insufficiency \\
\cline { 2 - 2 } & Untreated hypothyroidism \\
\hline
\end{tabular}

Table 5: Conditions that can elevate chloride values on sweat test.

The causes for a false positive sweat test are multiple and should be considered and evaluated in borderline scenarios such as this one. These are displayed on Table 5, being divided into primary or secondary, as the last ones can be treated, providing a normalized sweat test after its resolution $[4,11]$.

Concerning this case, caloric restriction was the appointed reason for this false positive.

The child returned to our appointment one year later with a normalized growth ratio, crossing percentile curves.

As doctors, we have no real awareness into the authentic feeding habits, unless we follow the child for $24 \mathrm{~h}$ or resort to hospital admission. But is it ethical to admit a child for these reasons, based on the theory that the parents are lying? For life-threatening conditions or neglect suspicions it can and should be done, but in this case the Social Services excluded neglect. This supports the need for health professionals to work as a team in a combined network of care.

A multidisciplinary team is a group composed by members with different and complementary experience, qualifications and skills that contribute to achieve specific objectives. Such teams are critical in identifying the aetiology of FT in infancy and early childhood and allow for simultaneous consideration of nutritional, medical and psychosocial risk factors associated with this complex syndrome [13]. Bithoney et al. [14] undertook a study comparing children with FT treated in a primary care setting with children followed in a multidisciplinary team clinic; growth outcomes were analysed 6 months later, with better results in the multidisciplinary group $(\mathrm{GQ}=1.75+/-0.39 \mathrm{SD})$, comparing to the primary care group $(\mathrm{GQ}=1.18+/-0.42 \mathrm{SD}, \mathrm{p}<0.001)$.

These diversified professionals should work together to investigate the possible cause of the FT, being crucial in these groups the presence of a dietician to identify dietary errors or deficits and work with the parents to overcome them, as well as social workers that investigate possible abuse or neglect.

The clinical team (physicians and nurses) should evaluate the growth progress over time and identify signs or symptoms pointing to specific causes or FT etiologies. Only then these children can be adequately treated or accomplished.

\section{Conclusion}

Malnourishment is a double-edged sword for its ability to mask chronic illness, meaning either a cause or a result of it. Identifying the problem underneath remains challenging due to our lack of control or knowledge of the real daily habits of our patients. A multidisciplinary approach is demanding as the effects of FT on cognitive development are unclear.

\section{References}

1. Homan G (2016) Failure to thrive: A practical guide. Am Fam Physician 94: 295-299.

2. Tavares M, Vaz Matos I, Bandeira A, Guedes M (2013) Abordagem da má evolução ponderal. Nascer e Crescer.

3. Wright $\mathrm{C}$ (2000) Identification and management of failure to thrive: $\mathrm{A}$ community perspective. Arch Dis Child 82: 5-9.

4. Fernandez J, Dominguez J, Suso J, Tascón A (2009) Manual de Diagnóstico y Terapéutica en Pediatria. Publimed.

5. Rafeeq M, Murad H (2017) Cystic fibrosis: Current therapeutic targets and future approaches. J Transl Med 15: 84.

6. Taylor C, Beckles-Willson N, Wolfe S (2001) The child with cystic fibrosis who fails to gain weight. J R Soc Med 40: 25-28.

7. Rosenstein B, Cutting G (1998) The diagnosis of cystic fibrosis: A consensus statement. Cystic fibrosis foundation consensus panel. J Pediatr 132: 589-595.

8. Silva Filho LV, Bussamra MH, Nakaie CM, Adde FV, Rodrigues JC, et al. (2003) Cystic fibrosis with normal sweat chloride concentration - Case report. Rev Hosp Clin Fac Med Sao Paulo 58: 260-262.

9. Mishra A, Greaves R, Massie J (2005) The relevance of sweat testing for the diagnosis of cystic fibrosis in the genomic era. Clin Biochem Rev 26: 135-153.

10. Massie J, Clements B (2005) Diagnosis of cystic fibrosis after new-born screening: the Australasian experience-twenty years and five million babies later: A consensus statement from the Australian Paediatric Respiratory Group. Pediatr Pulmonol 39: 440-446.

11. NCCLS (2000) Sweat testing: Sample collection and quantitative analysis; Approved Guideline-Second edition. Wayne: The Committee.

12. Lebecque P, Leal T, De Boeck C, Jaspers M, Cuppens H, et al. (2002) Mutations of the cystic fibrosis gene and intermediate sweat chloride levels in children. Am J Respir Crit Care Med 165: 757-761.

13. Peterson KE, Washington J, Rathbun JM (1884) Team management of failure to thrive. J Am Diet Assoc 84: 810-815.

14. Bithoney W, McJunkin J, Michalek J, Snyder J, Egan H, et al. (1991) The effect of a multidisciplinary team approach on weight gain in nonorganic failure-to-thrive children. J Dev Behav Pediatr 12: 254-258. 